\title{
RAMO RÊ SE RAI DÁ CERTO: O ENFRAQUECIMENTO \\ DA FRICATIVA /V/ NO FALAR DE FORTALEZA-CE
}

\author{
RAMO RÊ SE RAI DÁ CERTO: EL DEBILITAMIENTO DE LA FRICATIVA / V / EN EL HABLAR \\ DE FORTALEZA-CE
}

\author{
RAMO RÊ SE RAI DÁ CERTO: LENITION OF THE FRICATIVE/V/IN THE SPEECH OF \\ FORTALEZA-CE
}

\author{
Ana Germana Pontes Rodrigues* \\ Aluiza Alves de Araújo** \\ Maria Lidiane de Sousa Pereira*** \\ Universidade Estadual do Ceará
}

\begin{abstract}
RESUMO: Com base na sociolinguística variacionista, abordamos o comportamento variável da fricativa /v/ em início de palavra, no falar popular de Fortaleza, como em [v]ai (manutenção) [h] ai (enfraquecimento/aspiração/reificação). Objetivamos analisar quais fatores intralinguísticos e/ou extralinguísticos condicionam o enfraquecimento de $/ \mathrm{v} /$ no falar da capital cearense. Para tanto, analisamos a fala de 48 informantes disponíveis no acervo sonoro do NORPOFOR. As análises estatísticas realizadas com o auxílio do Goldvarb X apontam que a manutenção de /v/ ocorre em 93,4\% das ocorrências, enquanto que 6,6\% apresentam a variante aspirada. Verificamos também que são relevantes para o enfraquecimento de / $/ \mathrm{e}$, nessa mesma ordem, as seguintes variáveis intralinguísticas e extralinguísticas: dimensão do vocábulo (trissílabos ou maiores), faixa etária (falantes com 50 anos ou mais), frequência de uso (termo extremamente usual e termo usual), tonicidade (sílabas tônicas), escolaridade ( 0 -4 anos de escolarização) e

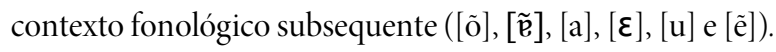

PALAVRAS-CHAVE: Enfraquecimento de /v/. Sociolinguística variacionista. Falar de Fortaleza.

RESUMEN: Con base en la sociolingüística variacionista, abordamos el comportamiento variable de la fricativa / v / en el inicio de la palabra, en el habla popular de Fortaleza, como en [v]ai (mantenimiento) [h]ai (aspiración / reificación). Objetivamos analizar qué factores intralingüísticos y / o extralingüísticos condicionan debilitamiento de /v/ en el hablar de la capital cearense. Para ello, analizamos el habla de 48 informantes disponibles en el acervo sonoro del NORPOFOR. Los análisis estadísticos realizados con la ayuda del Goldvarb X apuntan que el mantenimiento de / v / ocurre en el 93,4\% de las ocurrencias, mientras que el 6,6\% presenta la

\footnotetext{
* Doutoranda em Linguística Aplicada pelo Programa de Pós-Graduaça em Linguística Aplicada da Universidade Estadual do Ceará. É bolsista de doutorado pela FUNCAP e é professora efetiva da rede de ensino público do estado do Ceará. E-mail: anager_maninha@hotmail.com.

** Professora doutora do curso de Graduação em Letras e do Programa de Pós-Graduação em Linguística Aplicada da Universidade Estadual do Ceará. Atua na área de Linguística com ênfase em Sociolinguística Variacionista e Dialetologia.E-mail: aluizazinha@hotmail.com.

*** Doutoranda em Linguística Aplicada pelo Programa de Pós-Graduaça em Linguística Aplicada da Universidade Estadual do Ceará. Atualmente, é bolsista de doutorado pela CAPES. Atua na área de Linguística com ênfase em Sociolinguística.E-mail: lidianep.sousa@hotmail.com.
} 
variante aspirada. También verificamos que las variables intralingüísticas y extralingüísticas relevantes para el debilitamiento de / v /, y en ese mismo orden de importancia, son: dimensión del vocablo (trisílabos o mayores), grupo de edad (hablantes de 50 años o

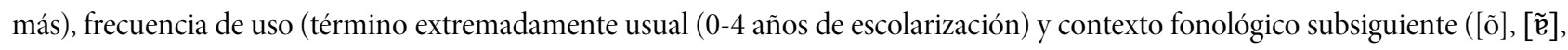
$[\mathrm{a}],[\varepsilon],[\mathrm{u}] \mathrm{y}[\tilde{\mathrm{e}}])$.

PALABRAS CLAVE: Debilitamiento de / v /. Sociolingüística variacionista. Hablar de Fortaleza.

ABSTRACT: Based on the variationist sociolinguistics, we sought to understand the behavior of the variable of the fricative / $/$ in the beginning of words, in the popular speech of Fortaleza, as in [v]ai (maintenance) [h]ai (aspiration/reification). We analyzed which intralinguistic and/or extralinguistic factors cause lenition of the $/ \mathrm{v} /$ in the speech of the Cearense capital. For that, we analyzed the speech of 48 informants available in the NORPOFOR database. The stylistic analysis, with the help of Goldvarb X, pointed the maintenance of the $/ \mathrm{v} /$ occurs in $93,4 \%$ of the occurrences, while $6,6 \%$ presented the aspired variant. We also verified the relevant intralinguistic and extralinguistic variables ranging over the lenition of / $/$ were, by relevance: word size (trissilable or bigger), age (speakers with 50 years or more), usage frequency (extremely usual terms and usual terms), tonicity (strong silables),

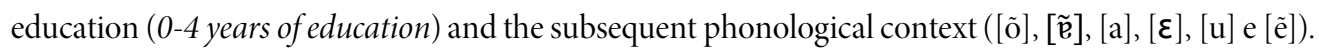

KEYWORDS: Weakening of the /v/. Variationist sociolinguistics. Speech of Fortaleza.

\section{INTRODUÇÃO}

O enfraquecimento ${ }^{1}[\mathrm{~h}] v s$. a manutenção da fricativa sonora /v/ é um fenômeno de variação linguística amplamente observado no português do Brasil (AGUIAR, 1937; MACAMBIRA, 1987; RONCARATI; UCHOA, 1988; CANOVAS, 1991; MARQUES, 2001; PELICIOLI, 2008). Hoje, sabemos que há diferentes contextos linguísticos que propiciam tanto a manutenção como o enfraquecimento da fricativa sonora. Dentre eles, destacamos a posição intervocálica, como no morfema verbal de pretérito imperfeito do indicativo de verbos na primeira conjugação $/ \mathrm{ava} /{ }^{2}$ : gosta[v]a (es)ta[h] $\mathrm{a}^{3}$; bem como em início de palavra: [v]ou $[\mathrm{h}] \hat{\mathrm{o}}^{4}$ (RODRIGUES, 2013). Reconhecendo que, no falar de Fortaleza-CE, a fricativa /v/ apresenta duas formas de realização, para este último contexto - aspiração vs. manutenção (realização plena) -, objetivamos analisar, neste estudo, a interferência de variáveis intralinguísticas e/ou extralinguísticas ${ }^{5}$ sobre o uso da variante aspirada no falar da capital cearense.

Acreditando que uma das melhores maneiras de observar a aspiração vs. manutenção de /v/ em início de palavra seja com base em dados reais de fala, selecionamos uma amostra de linguagem falada constituída por 48 informantes disponíveis no acervo sonoro do Projeto Norma Oral do Português Popular de Fortaleza (doravante NORPOFOR), sobre o qual tornaremos a falar na seção dedicada à metodologia do trabalho.

Visando atingir nosso objetivo, embasamos esta pesquisa nos pressupostos teórico-metodológicos da sociolinguística variacionista (WEINREICH; LABOV; HERZOG, 2006 [1968]; LABOV, 2008 [1972]). Surgida em meados da década de 1960, a sociolinguística variacionista figura hoje como uma vertente consagrada no campo dos estudos da linguagem e como uma das que mais contribuem com a observação e descrição do atual português do Brasil. Afinal, em nosso país, os pressupostos elencados pela sociolinguística variacionista encontraram um terreno fértil para serem testados. A rica diversidade linguística brasileira não passou despercebida e, nas palavras de Labov (2007, p. 3), “[...] alguns dos trabalhos mais importantes em variação linguística são feitos no Brasil”.

\footnotetext{
${ }^{1}$ Neste trabalho, os termos enfraquecimento, aspiração, reificação e glotalização são usados como sinônimos.

${ }^{2}$ Sobre a realização variável da fricativa /v/ no morfema verbal de pretérito imperfeito do indicativo de verbos na primeira conjugação /ava/, no falar de FortalezaCE, indicamos a leitura de Rodrigues e Araújo (2015).

${ }^{3}$ Ocorrências extraídas do inquérito (doravante Inq.) 06 do NORPOFOR.

${ }^{4}$ Ocorrências também extraídas do Inq. 06 do NORPOFOR.

${ }^{5}$ Em nossa metodologia, apresentamos detalhadamente cada um dos fatores intralinguísticos e extralinguísticos controlados, neste trabalho, bem como as hipóteses iniciais que levantamos para seus comportamentos.
} 
Em linhas gerais, a sociolinguística variacionista toma como principal objeto de observação a linguagem em uso, com foco nos inúmeros fenômenos de variação e mudança linguística inerentes a toda e qualquer língua natural. A partir disso, propõe, a seu modo, a observação das relações do fenômeno linguístico com a sociedade (MOLLICA, 2012 [2004]; CAMACHO, 2013). O ponto de partida é o reconhecimento de que nenhum fenômeno de variação e mudança linguística acontece de modo aleatório ou indiferente ao meio social em que determinada língua é usada. Por meio de uma metodologia apurada, os estudos variacionistas observam, dentre outras coisas, o quantum com que fatores intralinguísticos e/ou extralinguísticos condicionam (ou não) o uso das chamadas variantes linguísticas ${ }^{6}$ (TARALLO, 2001 [1986]; COAN; CARVALHO, 2016).

Importante colocar que, até a conclusão desta pesquisa, não tomamos conhecimento de nenhum outro estudo, na perspectiva variacionista, sobre o comportamento variável de /v/ em início de palavra, com dados do NORPOFOR. Isso certamente justifica a realização e confere maior relevância a este trabalho.

Na organização deste artigo, as três seções que se seguem a esta introdução correspondem: (i) a um breve panorama dos recentes estudos sociolinguísticos e dialetológicos acerca da manutenção vs. aspiração de /v/ no falar cearense; (ii) ao detalhamento dos principais procedimentos metodológicos percorridos para a realização deste trabalho e (iii) à apresentação e discussão dos resultados obtidos com esta pesquisa. Por último, tecemos algumas considerações finais.

\section{O FENÔMENO EM ESTUDO NO FALAR CEARENSE: OLHARES SOCIOLINGUÍSTICOS E DIALETOLÓGICOS}

Aragão (2009) observou a neutralização das fricativas /v, z, z/ e sua realização com a variante aspirada [h] do fonema /r/, utilizando o corpus do projeto Dialetos Sociais Cearenses (ARAGÃO; SOARES,1996), que fora obtido através de entrevistas, conversas espontâneas e IMP (Interação Médico-Paciente). Para tanto, a autora selecionou seis entrevistas e organizou a amostra de seu trabalho considerando as seguintes variáveis: sexo ${ }^{7}$; faixa etária (de 10 a 11 anos, de 14 a 15 anos e de 18 a 25 anos); grau de instrução (primário, ginásio e $2^{\circ}$ grau $)^{8}$ e classe social ( $\mathrm{B}$ - média e $\mathrm{C}$ - baixa).

Para efeito de comparação, Aragão (2009) utilizou também quatro inquéritos experimentais do projeto ALiB (Atlas Linguístico do Brasil), estado do Ceará, referentes à Fortaleza, com itens lexicais do QFF (Questionário Fonético-Fonológico) e do QSL (Questionário Semântico-Lexical), em que os falantes também foram distribuídos de acordo com o sexo (homens e mulheres); faixa etária (de 18 a 30 anos e de 45 a 60 anos); e grau de instrução (até a $4^{\mathrm{a}}$ série do Ensino Fundamental e Ensino Superior). Além disso, Aragão (2009) controlou os seguintes fatores linguísticos: estrutura fonética da palavra; diastráticos (registro culto e popular) e diatópicos (marca regional do fenômeno).

Seus resultados indicaram que, dos fatores linguísticos, os que mais marcaram o fenômeno em sua amostra foram: vogal seguinte

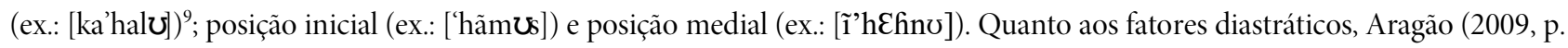
200) afirma que "[...] tanto os jovens como os mais idosos, homens e mulheres, com pouca ou muita escolaridade fazem a neutralização dos fonemas $/ v, z, 3, r /$ e usam a variante $[\mathrm{h}]$ ”. Segundo a autora, os fatores extralinguísticos que mais marcaram a realização do fenômeno estudado foram "[...] os estilos formal/informal, tenso/distenso, monitorado/não-monitorado." (ARAGÃO, 2009, p. 200). Em relação aos fatores diatópicos, ela concluiu que esse fenômeno é uma marca do falar cearense, como um todo, visto que ocorre em todos os segmentos sociais analisados. Portanto, a neutralização de /v, z, 3, r/ é fonético-fonológica e sócio-dialetal.

\footnotetext{
${ }^{6}$ Por variante linguística, entendemos, conforme Labov (2008 [1972]), as diferentes maneiras de dizer a mesma coisa do ponto de vista referencial do sistema. Todo fenômeno de variação e mudança linguística comporta, no mínimo, duas variantes linguísticas (MOLLICA, 2012 [2004]).

${ }^{7} \mathrm{O}$ uso dos termos sexo/gênero é feito com base no trabalho original.

${ }^{8}$ Atualmente correspondem, respectivamente, a: Ensino Fundamental I, Ensino Fundamental II e Ensino Médio.

${ }^{9}$ Nesta seção, todas as ocorrências usadas como exemplo foram extraídas dos trabalhos originais.
} 
No trabalho de Rodrigues, Araújo e Aragão (2013), a realização variável das fricativas /v, z, J/ foi observada na primeira divulgação dos resultados do Atlas Linguístico do Ceará (ALECE), publicado em 2010. A amostra usada no referido estudo encontra-se transcrita no volume II e abrange as respostas dadas a 21 questões dos inquéritos do ALECE. No entanto, as autoras se detiveram apenas em oito delas, cujas respostas envolvem o fonema /v/, como em: "ventania" (005), "orvalho" (024), "avós" (057), "ouvido" (078) e "cotovelo" (082). O objetivo principal foi o de registrar essas ocorrências e localizá-las no interior do Ceará.

As variáveis sócio-geolinguísticas analisadas foram ${ }^{10}$ : escolaridade (alfabetizado e analfabeto) e localização geográfica (Nordeste cearense, Centro-Leste cearense e Sul cearense). As variáveis linguísticas analisadas por Rodrigues, Araújo e Aragão (2013) foram: posição do segmento (ataque silábico e coda silábica) e tonicidade do segmento (tônica, pretônica e postônica). Os resultados foram obtidos com base apenas nas transcrições fonéticas apresentadas pelo projeto, visto que as autoras não tiveram acesso às gravações originais. As ocorrências de reificação de /v/ foram encontradas em apenas sete itens lexicais.

Quanto à posição do segmento, em relação à fricativa /v/, Rodrigues, Araújo e Aragão (2013) só obtiveram ocorrências em posição

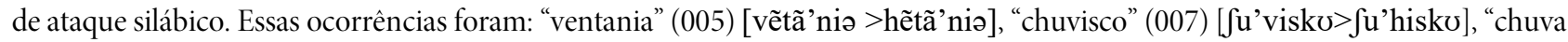

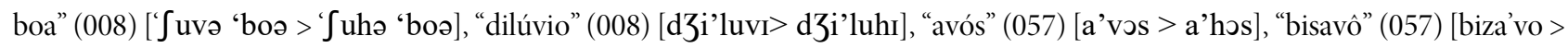

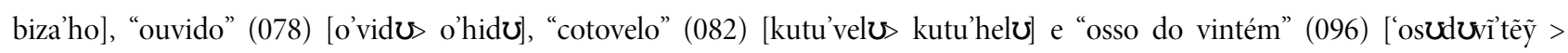
'osひdひhîtẽ̃̃].

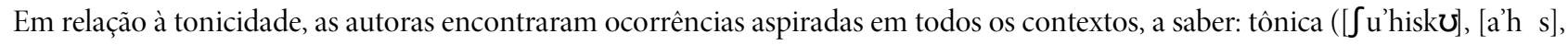

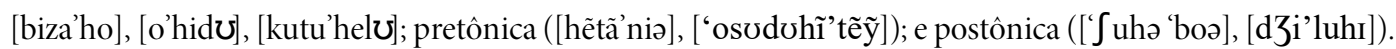

Quanto à escolaridade, em relação a /v, z, J/, foram encontradas 23 ocorrências de reificação, de um total de 32 (72\%), entre os informantes analfabetos; e nove (28\%) entre os alfabetizados. Quanto à localização geográfica, foi na mesorregião do Nordeste cearense que Rodrigues, Araújo e Aragão (2013) mais encontraram ocorrências de aspiração de /v z J/, seguida do Centro-Oeste e do Sul cearenses.

Rodrigues e Araújo (2015) observaram o enfraquecimento vs. manutenção da fricativa /v/ no morfema verbal de pretérito imperfeito do indicativo de verbos na primeira conjugação /ava/ no falar de Fortaleza. Assim como nesta pesquisa, as autoras também trabalharam com dados extraídos da fala de 48 informantes extraídos do Projeto NORPOFOR. Com um total de 1.816 ocorrências, os resultados de Rodrigues e Araújo (2015) indicam que, na amostra analisada, há o enfraquecimento de /v/ no morfema verbal de pretérito imperfeito do indicativo de verbos na primeira conjugação em 46,2\% dos casos e manutenção de /v/ em $53,8 \%$.

Dentre os fatores linguísticos e extralinguísticos controlados pelas autoras, destacaram-se, nessa mesma ordem de relevância: a escolaridade (0-4 anos); o tipo de registro (DID); a frequência de uso (termo muito usual e termo extremamente usual); a faixa etária (50 anos ou mais e 26-49 anos); o tipo de sílaba (não travada); o gênero/sexo (homens) e a dimensão do vocábulo (dissílabo).

Dentre os achados nos estudos de Aragão (2009), Rodrigues, Araújo e Aragão (2013) e Rodrigues e Araújo (2015), vemos que, no falar cearense, a fricativa $/ \mathrm{v}$ / pode realizar-se de diferentes modos e em diferentes contextos linguísticos, a partir de amostras de fala distintas. De igual modo, vimos que esse fenômeno é condicionado por uma série de fatores linguísticos (vogal seguinte, posição inicial, posição medial, posição do segmento, tonicidade do segmento, frequência de uso, tipo de sílaba, dimensão do vocábulo) e extralinguísticos (tipo de registro - DID -, sexo, escolaridade e faixa etária).

\section{PROCEDIMENTOS METODOLÓGICOS}

\subsection{A AMOSTRA E OS INFORMANTES}

${ }^{10}$ As variáveis sexo e idade não puderam ser visualizadas nessa divulgação do Atlas. 
A amostra de fala usada, neste estudo, foi extraída do acervo sonoro do Projeto NORPOFOR. Segundo Araújo (2011), o NORPOFOR foi desenvolvido com o objetivo de armazenar e disponibilizar material linguístico representativo do falar popular dos fortalezenses. As gravações do referido projeto ocorreram no período de agosto de 2003 a julho de 2006, sendo, portanto, o banco de dados de fala popular fortalezense mais atual do qual temos notícias.

Construído nos moldes da sociolinguística variacionista, o NORPOFOR é composto hoje por 198 informantes que, de acordo com Araújo (2011, p. 838), são: “[...] fortalezenses natos ou vieram morar nesta cidade com, no máximo, cinco anos de idade; possuem pais cearenses; nunca se ausentaram de Fortaleza por um período superior a dois anos consecutivos; mantêm residência fixa na capital cearense. Estes critérios foram adotados com o objetivo de neutralizar a interferência dos falares de outras regiões".

De igual modo, os informantes do NORPOFOR estão devidamente estratificados, segundo o sexo (masculino e feminino), a faixa etária (15 a 25 anos; 26 a 49 anos; e a partir dos 50 anos), a escolaridade (0 a 4 anos; 5 a 8 anos; e 9 a 11 anos) e o tipo de registro (Diálogo entre Informante e Documentador - DID; Diálogo entre dois Documentadores - D2; e Elocução Formal - EF). A partir de um recorte no quadro geral dos informantes que compõem o NORPOFOR, construímos a amostra de fala usada neste trabalho que está devidamente explicitada no Quadro 1:

\begin{tabular}{|c|c|c|c|c|c|c|c|c|}
\hline \multirow{4}{*}{$\begin{array}{c}\text { Registro } \\
\text { Escolaridade } \\
\text { Idade }\end{array}$} & \multicolumn{8}{|c|}{ Sexo } \\
\hline & \multicolumn{4}{|c|}{ Homem } & \multicolumn{4}{|c|}{ Mulher } \\
\hline & \multicolumn{2}{|c|}{ DID } & \multicolumn{2}{|c|}{ D2 } & \multicolumn{2}{|c|}{ DID } & \multicolumn{2}{|c|}{ D2 } \\
\hline & $0-4$ & 9-11 & $0-4$ & $9-11$ & $0-4$ & $9-11$ & $0-4$ & $9-11$ \\
\hline 15 a 25 anos & 2 & 2 & 2 & 2 & 2 & 2 & 2 & 2 \\
\hline 26 a 49 anos & 2 & 2 & 2 & 2 & 2 & 2 & 2 & 2 \\
\hline 50 em diante & 2 & 2 & 2 & 2 & 2 & 2 & 2 & 2 \\
\hline
\end{tabular}

Fonte: Adaptado de Araújo (2011,p. 839).

Legenda: DID (Diálogo entre Informante e Documentador); D2 (Diálogo entre Dois Informantes).

Conforme podemos observar no Quadro 1, nossa amostra é composta por 48 informantes, equilibradamente estratificados segundo o sexo, a idade, a escolaridade e o tipo de inquérito. Ao todo, foram selecionados dois informantes por célula. Sobre o controle das variáveis escolaridade e tipo de inquérito, convém destacar que, dentre os tipos de inquéritos, optamos por trabalhar apenas com os DID e D2, desprezando os inquéritos do tipo EF (Elocuções Formais). Para a escolaridade, por sua vez, selecionamos apenas informantes com 0-4 e 9-11 anos de escolarização, desprezando os de escolaridade intermediária (5-8 anos).

\subsection{LEVANTAMENTO DOS DADOS}

A partir dos inquéritos do NORPOFOR que selecionamos, demos início à transcrição fonética dos itens lexicais que continham /v/, em suas variantes aspirada e da manutenção em início de palavra. Durante a coleta dos dados, foram desprezados os vinte primeiros minutos de cada gravação, pois acreditamos que, após esse tempo, o informante não mais monitora sua fala diante da presença do gravador. Após a transcrição dos dados, feita de oitiva, definimos as variáveis dependente e independente controladas, neste trabalho, e que são descritas a seguir. 


\subsubsection{Variável dependente}

É aquela cujas variantes dependem de certos contextos (linguísticos e/ou extralinguísticos) para ocorrer com maior ou menor frequência. Nesta pesquisa, analisamos a realização variável da fricativa /v/ em início de palavra. Conforme já explicamos, /v/ pode se realizar como [v] (manutenção) ou como [h] (reificação), como em:

a) Realização plena (manutenção): eu ia [v]oltar né? (Inq. 99)

b) Reificação: amiga [h]ai começar o Fortal. (Inq. 99).

\subsubsection{Variáveis independentes}

As variáveis independentes foram estabelecidas com base na literatura pertinente e na audição dos inquéritos. Em um estudo sociolinguístico, as variáveis independentes podem ser tanto de natureza linguística como extralinguística:

- Variáveis linguísticas:

a) Contexto fonológico precedente

As variáveis contextos fonológicos precedente e subsequente podem exercer muita influência sobre as variantes aspiradas e com realização plena. Trata-se da noção de direcionalidade, a partir da qual podemos dizer se um segmento sonoro possui mais afinidade com o som que o precede ou com o que o sucede. Por isso, observamos aqui todos os elementos que circunvizinham as realizações do fonema $/ \mathrm{v} /$ e que podem condicionar sua manutenção ou aspiração ${ }^{12}$. Abaixo, apresentamos ocorrências para o contexto fonológico precedente:

- [a]: na /v/ida (Inq. 06)

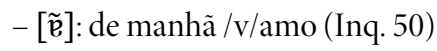

- [e]: você/v/ai (Inq. 06)

- [ع]: é/v/ocê (Inq. 06)

- [ẽ]: não houve ocorrência na amostra

- [i]: de /v/éa (Inq. 06)

- [ũ]: num /v/olta (Inq. 06)

- [w]; [u] $]^{1} \mathrm{eu} / \mathrm{v} / \hat{o}$ (Inq. 06)

- Consoante: às/v/eiz $\emptyset$ (Inq. 95)

b) Contexto fonológico subsequente

$$
\begin{aligned}
& -[\mathrm{a}]: / \mathrm{v} / \mathrm{ai} \text { (Inq. 06) } \\
& -[\tilde{\mathrm{e}}]: \text { /v/amo (Inq. 06) } \\
& -[\mathrm{e}]: / \mathrm{v} / \hat{e} \text { (Inq. 06) } \\
& -[\mathrm{E}]: / \mathrm{v} / \mathrm{e} i \text { (Inq. 95) } \\
& -[\tilde{e}]: / \mathrm{v} / \mathrm{em} \text { (Inq. 95) } \\
& -[\mathrm{i}]: \text { /v/ida (Inq. 06) } \\
& -[\tilde{1}]: / \text { v/inte (Inq. 06) }
\end{aligned}
$$

- [ĩ]: pra mim/v/ê (Inq. 50)

- [I]: mai /v/elho (Inq. 06)

- [o]: vô/v/oltá (Inq. 23)

- [0]: não houve ocorrência na amostra

- [õ]: bombom /v/inte (Inq. 36)

$-[\mathrm{u}]:$ pelo /v/ício (Inq. 06)

\footnotetext{
${ }^{11}$ Nesta seção, todas as ocorrências usadas para exemplificação foram extraídas dos inquéritos do NORPOFOR selecionados para este estudo.

${ }^{12}$ A transcrição apresentada aproxima-se o máximo possível da fala dos informantes, mas optamos por não transcrevê-la foneticamente, para não dificultar a leitura.
} 
c) Tipo de sílaba

A variável tipo de sílaba foi escolhida por supormos que o fato de uma sílaba ser travada ou livre poderia influenciar na ocorrência do fenômeno investigado. A seguir, ilustramos cada fator com ocorrências:

- Travada: /v/olta (Inq. 06)

- Não travada: /v/ida (Inq. 06)

d) Tonicidade do segmento

Em linhas gerais, as pesquisas sobre o fenômeno investigado (CANOVAS, 1991; MARQUES, 2001) têm revelado que as sílabas tônicas, por possuírem um traço mais saliente, tendem a ser mais suscetíveis a variações. Assim, resolvemos testar essa hipótese também com base em nossa amostra. A seguir, ilustramos cada fator com ocorrências:

- Tônica: /v/amo (Inq. 06); de/v/ia (Inq. 06)

- Pretônica: /v/ontade (Inq. 50); e/v/itá (Inq. 10)

e) Dimensão do vocábulo

A variável dimensão do vocábulo foi analisada para verificarmos se a extensão do mesmo exerce alguma influência sobre o fenômeno investigado. Acreditamos, juntamente com Marques (2001), que, quanto mais extenso for o vocábulo, maior será o enfraquecimento, ou seja, maior será o uso da variante aspirada. A seguir, como ilustração, para cada fator, apresentamos as seguintes ocorrências:

- Monossílabo: /v/ai (Inq. 06)

- Dissílabo: /v/amos (Inq. 67)

- Trissílabo ou maior: /v/iolência (Inq. 94)

f) Classes de palavras

Acreditamos que a variável classes de palavras pode influenciar o uso de /v/ (ROCARATI; UCHOA, 1988; MARQUES, 2001; ALENCAR, 2007). Uma observação a ser feita é que na classe Outros incluímos apenas as interjeições. A seguir, cada fator é ilustrado com ocorrências encontradas em nossos dados:

- Nomes: /v/ida (Inq. 06)

- Verbos: /v/ô (Inq. 06)

- Outros: /v/ixe (Inq. 50)

g) Frequência de uso

A variável frequência de uso do segmento, por sua vez, leva em consideração a hipótese proposta por Roncarati e Uchoa (1988) de que o fenômeno estaria lexicalmente condicionado, pois quanto mais determinada palavra precisar ser utilizada, maior será a sua variação. No entanto, utilizamos critérios diferentes desses autores.

Inicialmente, deixamos para codificar essa variável após todas as outras terem sido codificadas em nossa amostra. Em seguida, fizemos uma contagem de cada palavra que aparecia em nossos dados para, depois, poder agrupá-la ou não junto a outras que se modificavam apenas em algumas flexões. Por exemplo, num mesmo grupo, reunimos os vocábulos: "volta - volto - volte - voltam voltá - voltava - voltando - voltamo(s) - voltaram - voltado - voltarão - voltasse - voltei - voltô”. Juntas, elas contabilizam 148 ocorrências (de enfraquecimento e de manutenção). No entanto, nem todas as flexões de um mesmo verbo ficaram reunidas num 
mesmo grupo, pois possuíam características fonológicas bem diferentes. Exemplos disso são os verbos “vem” (com 131 ocorrências) e "vinha(m)" (com 86 ocorrências).

Por último, com o número de cada grupo de palavras em mãos, pudemos reuni-las a partir de intervalos estabelecidos de acordo com o número total que encontramos em cada contexto. Por exemplo: para o contexto de /v/, em início de palavra, obtivemos 998 realizações para a palavra com maior ocorrência ("vai"), por isso a classificamos como um termo extremamente usual; o fator que viria em segundo lugar, termos muito usuais, passaria a englobar as palavras que apresentassem um número inferior de ocorrências (neste fator, de 151-480, já que o grupo de palavras que apareceu em primeiro lugar, nesse segundo fator - "veze(s) - veiz(e) - veizinha - vez" -, obteve 430 ocorrências); para os fatores sucessores, inclusive com /v/, em contexto intervocálico, utilizamos esse mesmo critério. A seguir, exemplificamos cada fator:

- Termo extremamente usual (de 481-1000): /v/ai (Inq. 06)

- Termo muito usual (de 151-480): /v/ê (Inq. 06)

- Termo usual (de 61-150): /v/iu (Inq. 06)

- Termo pouco usual (de 21-60): /v/iolência (Inq. 94)

- Termo pouquíssimo usual (de 01-20): /v/inho (Inq. 10)

- Variáveis extralinguísticas:

Estas variáveis levam em conta os aspectos sócio-culturais e estilísticos que envolvem os falantes, tais como: sexo, faixa etária, escolaridade e monitoramento estilístico. Essas variáveis têm sido muito utilizadas por diversos autores que pesquisaram sobre o enfraquecimento de fricativas no português falado no Brasil. Assim, resolvemos testar essas variáveis também no falar de FortalezaCE.

a) Sexo

Labov (1994), ao reconhecer diferenças no comportamento linguístico de homens e mulheres, elaborou alguns princípios básicos sobre isso. O primeiro deles é que, normalmente, os homens tendem a usar mais as formas não padronizadas (também chamadas de inovadoras). Por outro lado, as mulheres tendem a favorecer mais o uso das formas padronizadas (também chamadas conservadoras) do que os homens. No entanto, na mudança linguística, geralmente são as mulheres que se mostram mais inovadoras, utilizando as formas novas (desde que estas sejam prestigiadas) bem mais do que os homens. Esses princípios levam em consideração as atitudes sociais de cada sexo.

Para a observação da variável sexo em nosso estudo, dividimos este grupo em:

- Masculino;

- Feminino.

No que tange ao comportamento da variável sexo, neste estudo, acreditamos que os homens favorecem a aspiração de /v/ em início de palavras. Em contrapartida, acreditamos que são as mulheres que inibem o uso dessa variante linguística.

b) Faixa etária

A sociolinguística variacionista postula que os fenômenos de variação e mudança linguística podem ser apreendidos durante a sua implementação, através do que se denominou análise em tempo aparente. Levamos em consideração, ainda, a hipótese clássica, segundo a qual: "[...] o comportamento linguístico de cada geração reflete um estágio da língua, com os grupos etários mais jovens introduzindo novas alternantes que substituem gradativamente aquelas que caracterizam a fala de indivíduos de faixas etárias mais velhas" (ARAÚJO, 2007, p. 395). 
Diante disso, buscamos analisar e comparar a linguagem de sujeitos com diferentes faixas etárias sobre a manutenção ou aspiração da fricativa /v/ em nossa amostra. A partir disso, foi possível verificar se o fenômeno aqui analisado apresenta indícios de mudança em progresso ou de variação estável. As faixas que analisamos são as mesmas estabelecidas no Projeto NORPOFOR:

- 15-25 anos;

-26-49 anos;

-50 anos em diante.

Para a faixa etária, nossas expectativas são as de que os falantes com 15-25 anos beneficiem o uso da variante aspirada, ao contrário dos falantes com 26-49 e com mais de 50 anos.

c) Escolaridade

A variável escolaridade frequentemente aparece nas pesquisas sociolinguísticas, visto que, geralmente, os falantes com menor nível de escolaridade são os que mais usam as formas não padrão. Normalmente, é na escola onde o indivíduo é mais exposto ao conhecimento sistematizado da língua e à sua forma padrão.

Neste trabalho, levamos em consideração apenas falantes sem ensino superior completo. Assim, decidimos controlar a variável escolaridade a partir da estratificação dos informantes também estabelecida pelo Projeto NORPOFOR, descartando a faixa intermediária (5-8 anos de escolaridade). Desse modo, selecionamos para análise falantes com:

- 0-4 anos;

-9-11 anos.

Diante do que colocamos acerca da variável escolaridade, esperamos que os falantes com 0-4 anos favoreçam a aspiração de /v/ em início de palavra, ao contrário dos falantes com 9-11 anos de escolarização.

d) Tipo de inquérito

Nessa variável, analisamos o tipo de discurso que envolve cada informante. Em nossa amostra, trabalhamos com dois tipos de inquéritos diferentes: DID e D2. Acreditamos que situações de maior “pressão", como o fato de o informante não se sentir à vontade com o documentador ou mesmo de saber que sua fala está sendo gravada, tendem a causar um maior monitoramento e controle linguístico, por parte do falante. Por outro lado, situações mais "relaxadas", como o relato de uma experiência pessoal, tendem a favorecer uma fala menos monitorada, conhecida pela sociolinguística como vernáculo.

Em geral, espera-se que no DID os informantes apresentem um comportamento, de certa forma, monitorado (não relaxado), o que pode ser um reflexo da presença do inquiridor e do gravador, embora, conforme já mencionamos, a nossa escolha pela audição dos quarenta minutos ${ }^{13}$ finais da gravação procure eliminar um pouco esse controle exercido.

No D2, por sua vez, espera-se que o informante apresente um discurso mais relaxado. Em geral, esse tipo de inquérito foi realizado entre duas pessoas que já se conheciam e tinham certo grau de intimidade, fato que poderia eliminar boa parte do monitoramento na fala dos informantes. Dessa maneira, espera-se que haja um maior número de variantes inovadoras nesse estilo de fala. Dito isso, analisamos, na variável tipo de inquérito, os fatores:

- DID;

$-\mathrm{D} 2$.

${ }^{13}$ Obviamente, esse tempo foi menor quando a gravação possuía menos de 40 minutos. 


\section{APRESENTAÇÃO E DISCUSSÃO DOS RESULTADOS}

Ao todo, localizamos 5.962 ocorrências para a variação entre a manutenção vs. aspiração da fricativa /v/ em início de palavra no falar de Fortaleza-CE. Com o auxílio do programa de análise estatística Goldvarb X (SANKOFF; TAGLIAMONTE; SMITH, 2005), descobrimos que, do total de ocorrências do fenômeno investigado (após a eliminação dos nocautes), 383 (6,4\%) pertenciam à forma aspirada e $5.579(93,6 \%)$ correspondiam à manutenção de /v/, conforme mostra o Gráfico 1 :

Gráfico 1: Frequência de uso das variantes investigadas

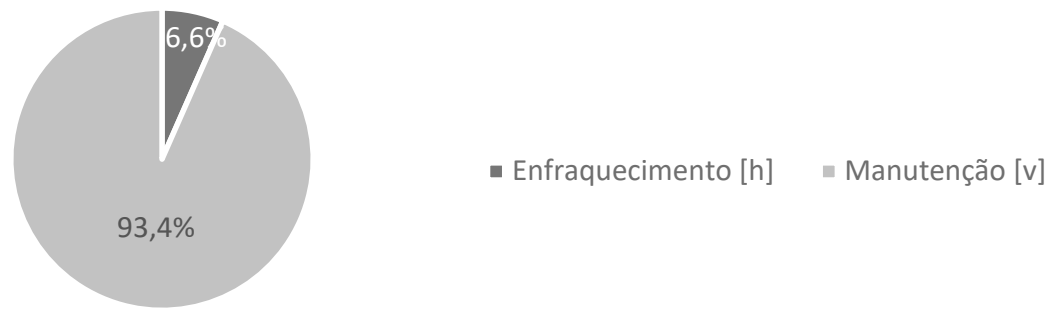

Fonte: Elaborado pelas autoras

Esses resultados confirmam nossa hipótese inicial para o comportamento de /v/ em início de palavra no falar de Fortaleza, pois acreditávamos que esse fonema poderia acontecer tanto de forma plena (manutenção) como de modo aspirado. Além de nos indicar as frequências de uso das variantes investigadas no comportamento variável da fricativa /v/ em início de palavra, o Goldvarb X também indicou as variáveis linguísticas e extralinguísticas estatisticamente relevantes para o fenômeno no falar de Fortaleza-CE, bem como o peso relativo ${ }^{14}$ obtido para cada um dos fatores que compõem as variáveis testadas.

Assim, foram apontadas como pertinentes para o fenômeno investigado, em nossa amostra e, nessa mesma ordem de importância, as seguintes variáveis: dimensão do vocábulo, faixa etária, escolaridade, frequência de uso, tonicidade, tipo de sílaba e contexto fonológico subsequente. Em contrapartida, as variáveis excluídas, também nessa ordem, foram: tipo de sílaba, classes de palavras, contexto fonológico precedente, monitoramento estilístico e sexo. A exclusão dessas variáveis refuta nossas expectativas iniciais quanto aos seus comportamentos, já que esperávamos que elas também se mostrassem estatisticamente relevantes para este estudo.

Importante mencionar que o fator tipo de sílaba foi selecionado e, ao mesmo tempo, excluído pelo programa. Sobre tal situação, Guy e Zilles (2007, p. 166) comentam que isso: “[...] só ocorre quando se trata de uma análise complexa (com muitos grupos de fatores), e quando os grupos não são completamente ortogonais, em termos da distribuição dos dados. Por exemplo, há um grupo de fatores que se sobrepõe parcialmente a outro grupo: alguns dos fatores nos dois grupos descrevem os mesmos dados".

Quando tal fato ocorre, os autores propõem que o pesquisador procure entender melhor por que obteve esse resultado, fazendo cruzamento entre os grupos envolvidos, para averiguar onde se encontra a maioria dos dados. Após analisarmos cada subfator, verificamos que o termo pouco usual e o termo pouquíssimo usual obtiveram ocorrências muito baixas (11 e 4, respectivamente). Decidimos, então, amalgamá-los, afinal, "[...] é sumamente improvável que qualquer fator com muito poucos dados vá ter significância estatística; esse é certamente o caso para os que têm menos de 10 ocorrências, e provavelmente o seja para os que têm menos de 15” (GUY; ZILLES, 2007,p. 170).

Feito o amálgama, os resultados obtidos mostram uma leve alteração apenas nos valores dos pesos relativos, mas não na relevância de cada um para este trabalho, muito menos nos valores das frequências de uso das variantes. Além disso, nessa rodada, nenhum outro fator selecionado foi também excluído. A nova disposição dos fatores foi, portanto, a seguinte: dimensão do vocábulo, faixa etária, frequência de uso, tonicidade, escolaridade e contexto fonológico subsequente. Já os fatores excluídos foram os mesmos e na mesma ordem da rodada sem amálgama, conforme já explicitamos.

\footnotetext{
${ }^{14}$ A partir do modelo logístico apresentado pelo programa GoldVarb X, a média do grupo de fatores é ponderada pelo número de dados empíricos de que se dispõe para cada fator com o objetivo de evitar que fatores que apresentam poucos dados tenham maior influência no cálculo. Com isso, esse programa irá fornecer o número de ocorrências das variantes analisadas para cada fator, o percentual de aplicação da regra e o peso relativo (P.R.), que poderá ser neutro (0,50), favorecedor (acima de 0,50) ou desfavorecedor (abaixo de 0,50) em relação à aplicação da regra em estudo (GUY; ZILLES, 2007).
} 
É válido dizer que, embora a frequência de uso da manutenção de /v/ tenha sido significativamente superior a sua aspiração, todas as rodadas no Goldvarb X foram realizadas em função da variante aspirada. Nosso posicionamento pode ser justificado, pois já que a variante aspirada é tida como não padronizada - embora esteja presente no falar dos fortalezenses, assim como em outras variedades do português do Brasil, conforme indicamos na seção 2 -, é importante apontar quais fatores linguísticos e/ou extralinguísticos condicionam seu uso, comprovando, assim, que ela não ocorre aleatoriamente na comunidade de fala estudada. Ressaltamos ainda que o melhor nível de análise apresentado pelo Goldvarb X foi o do step up 48 (input 0,033, significância 0,000 e log likelihood-1165,716). Na sequência, apresentamos e discutimos o conjunto de grupos de fatores relevantes para esta pesquisa, conforme a ordem de seleção estatística.

a) Dimensão do vocábulo

Para esse fator, defendíamos a hipótese de que quanto mais extenso o vocábulo, maior a probabilidade de enfraquecimento da fricativa /v/. Mollica e Mattos (1989 apud MARQUES, 2001), sobre o apagamento do fonema /d/ no grupo “-ndo”, afirmam que, quando o vocábulo é grande, os segmentos tendem a não se realizar. De igual modo, Votre e Callou (apud MARQUES, 2001) confirmam essa hipótese a respeito do segmento /-r/, que apresentou uma tendência a ser mantido em vocábulos menos extensos e sofreu apagamento nos mais extensos.

Em nossa amostra, dentre os dados com até quinze ocorrências aspiradas, encontramos as outras onze ocorrências de trissílabos ou maiores: "e [h] oltava" (Inq. 95), "uma [h] acaria" (Inq. 95), "de [h] agabundo” (Inq. 95), "uma [h]erdade” (Inq. 95), "sem [h]ergonha” (Inq. 95), "sem [h]ergonha” (Inq. 49), "da [h] agabundagem" (Inq. 132), "uma [h] eizinha” (Inq. 23), "boa [h] ontade” (Inq. 103) e "tenho [h] ontade” (Inq. 19). Sobre os resultados obtidos para a variável dimensão do vocábulo, vejamos a Tabela 1:

Tabela 1: Atuação da variável dimensão do vocábulo sobre o enfraquecimento de /v/ no início de palavra

\begin{tabular}{|c|c|c|c|c|}
\hline Fatores & Aplica/Total & $\%$ & P.R. & Exemplo \\
\hline Trissílabos ou maiores & $11 / 569$ & 1,9 & 0,735 & e [h] oltava \\
\hline Monossílabos & $293 / 2554$ & 11,5 & 0,517 & eu [h]ô \\
\hline Dissílabos & $77 / 2627$ & 2,9 & 0,429 & toda $[\mathrm{h}]$ ida \\
\hline
\end{tabular}

Fonte: Elaborada pelas autoras

De acordo com a Tabela 1, os vocábulos com três ou mais sílabas são os únicos que favorecem o enfraquecimento de /v/ (0,735), já que os vocábulos monossílabos apresentam um comportamento discreto em relação a essa regra, como mostra seu peso relativo próximo ao ponto neutro $(0,517)$. Os dissílabos atuam no sentido de bloquear o emprego da variante aspirada $(0,429)$.

Observando o conjunto dos pesos relativos obtidos para a variável dimensão do vocábulo, confirma-se a hipótese de que quanto mais extenso o vocábulo, maior a probabilidade de ocorrer o enfraquecimento.

b) Faixa etária

Tabela 2: Atuação da faixa etária sobre o enfraquecimento de /v/ no início de palavra

\begin{tabular}{|c|c|c|c|}
\hline Fatores & Aplica/Total & $\%$ & P.R. \\
\hline 50 anos ou mais & $170 / 1811$ & 9,4 & 0,641 \\
\hline 26-49 anos & $123 / 1980$ & 6,2 & 0,479 \\
\hline \multirow[t]{2}{*}{ 15-25 anos } & $88 / 1959$ & 4,5 & 0,388 \\
\hline & \multicolumn{2}{|c|}{ Fonte: Elaborada pelas autoras } & \\
\hline
\end{tabular}


Com a observação da variável faixa etária, nossos dados indicam, conforme a Tabela 2, que quanto mais jovem for o informante, menor será o uso da variante enfraquecida $(0,388)$. Por outro lado, a faixa etária de 50 anos ou mais $(0,641)$ aparece como a única que favorece o enfraquecimento de /v/, já que a faixa constituída por falantes com 26 a 49 anos $(0,479)$ e a de 15 a 25 anos $(0,388)$ se mostraram inibidoras da regra.

É bom frisar que esses resultados para a variável faixa etária não confirmam nossas expectativas iniciais, pois acreditávamos que os falantes mais jovens, ao contrário do que vemos, estariam favorecendo a aspiração de /v/ em início de palavra.

c) Frequência de uso do vocábulo

Tabela 3: Atuação da frequência de uso sobre o enfraquecimento de /v/ no início de palavra

\begin{tabular}{|c|c|c|c|c|}
\hline Fatores & Aplica/Total & $\%$ & P.R. & Exemplo \\
\hline Termo extremamente usual & $229 / 2116$ & 10,8 & 0,667 & inda $[\mathrm{h}] \mathrm{ai}$ \\
\hline Termo usual & $94 / 1371$ & 6,9 & 0,557 & num $[\mathrm{h}]$ inha \\
\hline Termo muito usual & $43 / 1086$ & 4,0 & 0,469 & mai [h] elho \\
\hline $\begin{array}{l}\text { Termo pouco usual e } \\
\text { pouquíssimo usual }\end{array}$ & $11 / 638$ & 1,7 & 0,199 & num $[\mathrm{h}]$ ota \\
\hline
\end{tabular}

Dentre os dados com até quinze ocorrências, encontramos outras onze ocorrências para os fatores 'termo pouco usual' e 'termo pouquíssimo usual': "uma [h]erdade" (Inq. 95), "boa [h] ontade" (Inq. 103), "tenho [h]ontade” (Inq. 19), "eu [h] enho" (Inq. 19), "num [h]ia” (Inq. 143), "sem [h] ergonha” (Inq. 153 e 49), "num [h]oto” (Inq. 132), "num [h]otei” (Inq. 132).

Com base na Tabela 3, verificamos que o fator frequência de uso apresentou resultados um pouco divergentes das nossas hipóteses. Inicialmente, confirmamos que os 'termos extremamente usuais' $(0,667)$ são os maiores aliados do enfraquecimento de /v/ e os subfatores amalgamados (termo pouco usual e termo pouquíssimo usual) continuaram com um peso relativo irrelevante $(0,199)$, conforme indica a Tabela 3 .

No entanto, em segundo lugar, aparece o fator 'termo usual' $(0,557)$, e não o 'termo muito usual' $(0,469)$, que mais beneficia a variante aspirada. A explicação que encontramos inicialmente para isso foi a de que o 'termo muito usual' ocorre mais vezes do que o 'termo usual', mas não com a variante aspirada. Para entendermos melhor o porquê disso, observamos o comportamento desse fator diante de outros em cada nível da rodada e verificamos que, novamente, o fator contexto fonológico subsequente estava influenciando o resultado desses fatores. Daí veio a necessidade de realizarmos um cruzamento entre a frequência de uso e o contexto fonológico subsequente.

Feito o cruzamento, como mostra a Tabela 4, observamos que a maior concentração dos dados se dá apenas na vogal [a], causando um desequilíbrio em relação às ocorrências das demais vogais. Verificamos ainda que, entre os 'termos muito usuais', não encontramos nenhum exemplo com a vogal [a] como subsequente a /v/ e, entre os 'termos usuais', encontramos alguns com a palavra "vá" (nos inquéritos 67, 10, 93, 153, 34, 19, 59 e 143). Dessa forma, explica-se o porquê de um fator se sobrepor ao outro. Esse cruzamento é apresentado na Tabela 4. 
Tabela 4: Contexto fonológico subsequente x frequência de uso sobre o enfraquecimento de /v/ no início de palavra

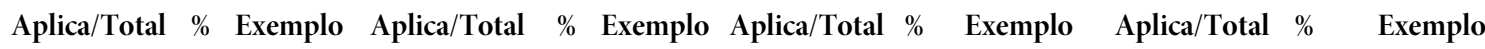

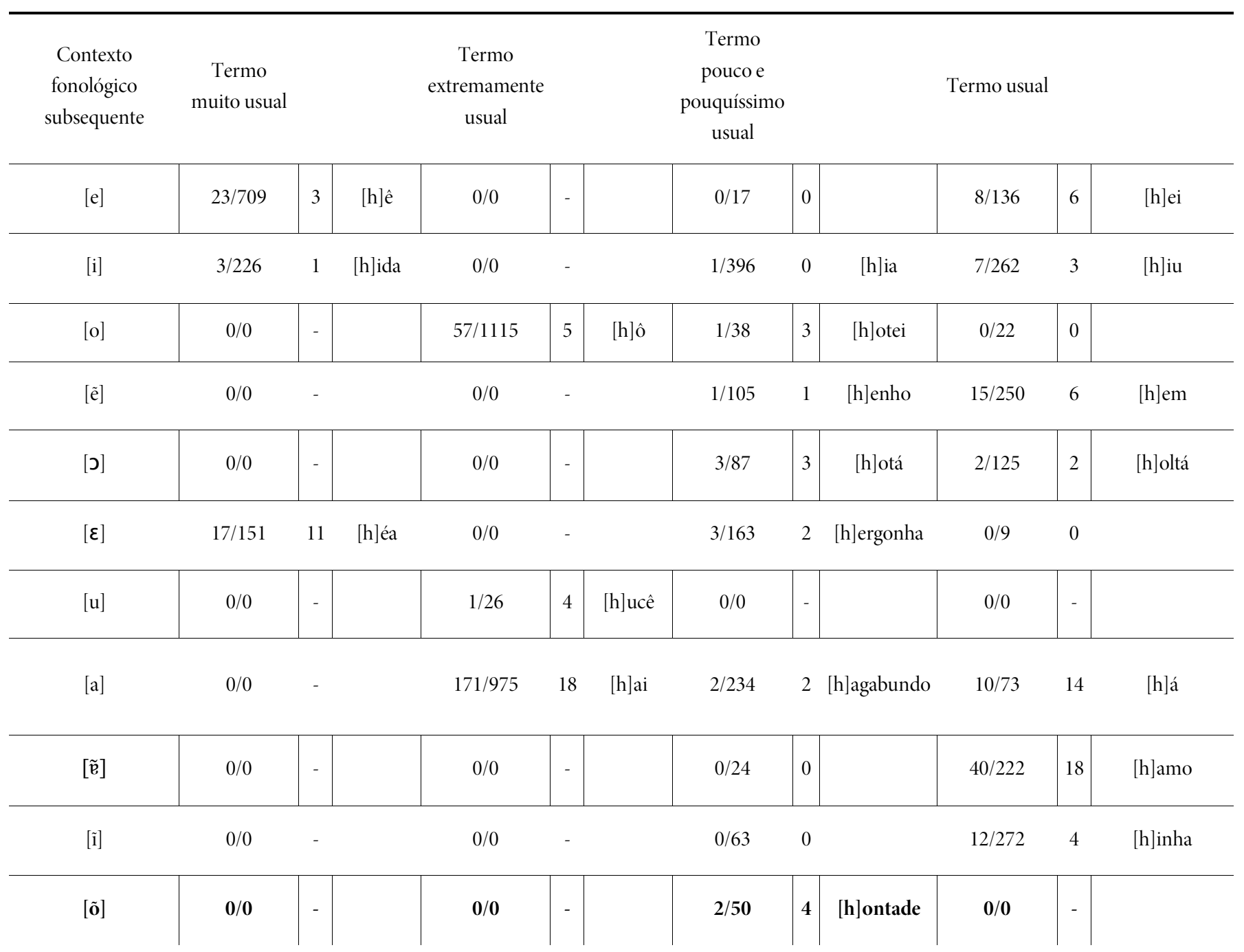

Fonte: Elaborada pelas autoras

Dessa forma, observamos que os 'termos extremamente usuais' são os mais relevantes da variável frequência de uso do vocábulo, no sentido de favorecer a aspiração de /v/.

d) Tonicidade

Quanto à variável tonicidade, constatamos, conforme a Tabela 5, que somente as sílabas tônicas $(0,592)$ favorecem o enfraquecimento de $/ \mathrm{v} /$, já que as pretônicas inibem a variante aspirada $(0,263)$.

Tabela 5: Atuação da tonicidade sobre o enfraquecimento de /v/ no início de palavra

\begin{tabular}{|c|c|c|c|c|}
\hline Fatores & Aplica/Total & $\%$ & P.R. & Exemplo \\
\hline Tônicas & $357 / 4228$ & 8,4 & 0,592 & pra $[\mathrm{h}] \mathrm{i}$ \\
\hline Pretônicas & $24 / 1522$ & 1,6 & 0,263 & de [h]agabundo \\
\hline
\end{tabular}


Para entendermos melhor a atuação desse fator, é interessante verificarmos o conceito de saliência fônica. Segundo Guy (1986, apud ARAÚJO, 2000, p. 89), “[...] os traços mais salientes são aprendidos mais rapidamente por serem mais perceptíveis.” Assim, as formas inovadoras são inicialmente introduzidas nesses ambientes para, apenas posteriormente e, de maneira mais fraca, atingirem os ambientes com saliência mínima. Isso explica o fato de as sílabas tônicas terem favorecido a aspiração de /v/, em nossa amostra.

e) Escolaridade

Tabela 6: Atuação da escolaridade sobre o enfraquecimento de /v/ no início de palavra

\begin{tabular}{|c|c|c|c|}
\hline Fatores & Aplica/Total & $\%$ & P.R. \\
\hline 0 a 4 anos & $232 / 2622$ & 8,8 & 0,617 \\
\hline 9 a 11 anos & $149 / 3128$ & 4,8 & 0,401 \\
\hline
\end{tabular}

Com relação à escolaridade, os resultados deste estudo indicam que a aspiração de /v/ se apresenta como uma forma estigmatizada, pois a menor escolaridade $(0,618)$, até 4 anos de escolarização, favorece o enfraquecimento, enquanto a maior escolaridade $(0,401)$, de 9 a 11 anos, inibe o seu uso, como indica a Tabela 6.

Destacamos que esses resultados confirmam nossa hipótese inicial para a atuação da escolaridade sobre a aspiração de /v/ em início de palavra. Acreditávamos mesmo que os falantes com 0-4 anos, isto é, com a menor escolaridade favoreceriam o uso da variante aspirada. Também supúnhamos que os falantes com 9-11 inibiriam o uso da mesma variante. Tais expectativas, conforme podemos observar na Tabela 6, de fato se confirmaram.

f) Contexto fonológico subsequente

Tabela 7: Atuação do contexto subsequente sobre o enfraquecimento de /v/ no início de palavra

\begin{tabular}{|c|c|c|c|c|}
\hline Fatores & Aplica/Total & $\%$ & P.R. & Exemplo \\
\hline$[\tilde{o}]$ & $2 / 50$ & 4,0 & 0.811 & boa $[\mathrm{h}]$ ontade \\
\hline$[\tilde{\mathfrak{E}}]$ & $40 / 246$ & 16,3 & 0.800 & menino [h]ão \\
\hline$[\mathrm{a}]$ & $185 / 1282$ & 14,4 & 0.673 & num $[\mathrm{h}] \mathrm{ai}$ \\
\hline$[\varepsilon]$ & $20 / 323$ & 6,2 & 0.665 & continha [h]éa \\
\hline$[\mathrm{u}]$ & $1 / 26$ & 3,8 & 0.576 & se $[\mathrm{h}] \mathrm{ucê}$ \\
\hline$[\tilde{e}]$ & $16 / 355$ & 4,5 & 0.549 & num [h]em \\
\hline$[\mathrm{o}]$ & $58 / 1175$ & 4,9 & 0.462 & $\mathrm{eu}[\mathrm{h}] \hat{\mathrm{o}}$ \\
\hline$[\mathrm{e}]$ & $31 / 862$ & 3,6 & 0.436 & às [h]eze \\
\hline [כ] & $5 / 212$ & 2,4 & 0.412 & pa [h]oltá \\
\hline$[\tilde{1}]$ & $12 / 335$ & 3,6 & 0.341 & num [h]inha \\
\hline$[\mathrm{i}]$ & $11 / 884$ & 1,2 & 0.257 & ela $[\mathrm{h}] \mathrm{iu}$ \\
\hline
\end{tabular}




\section{Fonte: Elaborada pelas autoras}

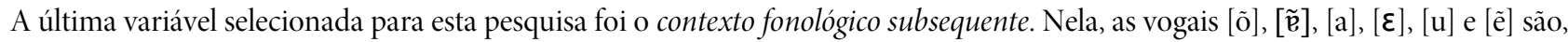
nesta ordem hierárquica, aliadas do enfraquecimento de /v/, enquanto as demais inibem o fenômeno. A vogal [õ] apresenta a melhor posição na escala de favorecimento da aspirada, mas observamos que ela só ocorreu duas vezes com a variante aspirada, sendo ambas com a mesma palavra: [h]ontade (Inq. 103 e 19).

Outro fator relevante foi a vogal $[\mathrm{u}]$, mas que só obteve uma ocorrência enfraquecida, conforme a Tabela 7. Dentre os segmentos desfavoráveis à variante aspirada e com menor número de dados, encontramos: a vogal [0], com apenas cinco ocorrências (as outras quatro são: "e [h]oltava" - Inq. 95, "num [h]otá" - Inq. 95 e 132, "num [h]oto" - Inq. 132), a vogal [ĩ], com doze dados (as outras onze ocorrências de [ĩ]: "gente [h]inha" - Inq. 95, "pa [h]im" - Inq. 95, "e [h]im" - Inq. 95, "sempe [h]inha" - Inq. 95, "que [h]inha" - Inq. 129, "em [h]inte" - Inq. 111, "quando [h]inha" - Inq. 10, "e [h]im" - Inq. 157, "aí [h]im" - Inq. 19, "num [h]im” - Inq. 19, "que [h]im" - Inq. 19), e a vogal [i], com onze ocorrências (as outras dez ocorrências de [i]: "toda [h]ida" - Inq. 06 e 06, "pra [h]i" Inq. 95, "mai [h]i" - Inq. 95, "num [h]i" - Inq. 95, "a [h]ida" - Inq. 46, "movimento [h]iu" - Inq. 153, "[h]iu” - Inq. 132, "cê [h]iu" Inq. 132).

\section{CONSIDERAÇÕES FINAIS}

Neste estudo, observamos a manutenção $v$ s. aspiração da fricativa /v/ em início de palavra no falar da capital cearense. A amostra de fala usada aqui foi construída com base no falar de 48 informantes extraídos do acervo sonoro do projeto NORPOFOR. Os resultados indicam que, conforme esperávamos, /v/ pode se realizar tanto de forma plena (manutenção) e/ou de modo aspirado, no falar dos fortalezenses.

De igual modo, verificamos também que esse fenômeno é condicionado por uma série de fatores de natureza linguística e extralinguística. Assim, o enfraquecimento, embora ocorra em apenas 6,6\% dos dados da amostra, é favorecido quando: os vocábulos são trissílabos ou maiores; a faixa etária é de 50 anos ou mais; a frequência de uso está entre os termos mais usuais (extremamente usual e usual); o segmento está na sílaba tônica; a escolaridade é igual a 0-4 anos; quando as vogais [õ], [e)], [a], [ع], [u] e [ẽ] estiverem sucedendo $/ \mathrm{v} /$.

Esses resultados indicam ainda que, na amostra deste trabalho, a aspiração de / $\mathrm{v}$ / figura como um fenômeno estigmatizado, tendo em vista que foi favorecido por informantes com o menor grau de escolaridade (0-4), enquanto que falantes com 9-11 anos de escolarização atuaram no sentido de inibir a aspiração de /v/. Com isso, vemos que, no falar da capital cearense, quanto menor a escolaridade, maiores as chances de haver a aspiração da fricativa $/ \mathrm{v} /$.

Quanto ao comportamento da variável faixa etária, averiguamos, conforme já indicamos, que são os falantes mais velhos (50 anos ou mais) que favorecem a variante aspirada. Esse resultado pode ser indício de um possível fenômeno de mudança em curso, no sentido de desfavorecer a variante aspirada em relação à manutenção, já que esperávamos dos falantes mais velhos uma postura mais conservadora diante do fenômeno investigado. Em outras palavras, acreditávamos que os falantes mais velhos, ao contrário do que ocorreu, estivessem inibindo a aspiração de /v/.

Evidentemente, esse último ponto merece ser mais bem explorado em um trabalho futuro e de maior amplitude. E, embora isso não seja possível, neste primeiro momento (devido ao espaço destinado aos artigos), acreditamos que, com este trabalho, deixamos uma significativa contribuição para a descrição do português atual falado na capital cearense. Esperamos com ele contribuir para pesquisas futuras (em nível de comparação) sobre o comportamento variável de /v/ em início de palavra, não somente no falar de Fortaleza, mas também, na medida do possível, no falar de outras localidades do país. 


\section{REFERENCIAS}

AGUIAR, M. de. Fonética do português do Ceará. Revista do Instituto do Ceará, Fortaleza, ano 51, n. 51, p. 271-307, 1937.

ALENCAR, M. S. M. de. Aspectos sócio-dialetais da língua falada em Fortaleza: as realizações dos fonemas /r/ e /r/. 2007. 184 f. Tese (Doutorado em Linguística) - Programa de Pós-Graduação em Linguística, Universidade Federal do Ceará, Fortaleza, 2007. Disponível em: <http://www.repositorio.ufc.br/handle/riufc/6109>. Acesso em: 03 abr. 2017.

ARAGÃO, M. do S. S. de. Estudos Fonético-Fonológicos no Estado do Ceará. Signum: Estudos de Linguagem, Londrina, v. 7/1, p. 21-41, jun. 2009. Disponível em: <http://www.uel.br/revistas/uel/index.php/signum/article/view/3730>. Acesso em: 04 abr. 2017.

ARAÚJO, A. A. de. A monotongação na norma culta de Fortaleza. 2000. 110f. Dissertação (Mestrado em Linguística) - Programa de Pós-Graduação em Linguística, Universidade Federal do Ceará, Fortaleza, 2000.

O projeto Norma Oral do Português Popular de Fortaleza - NORPOFOR. In: CONGRESSO NACIONAL DE LINGUíSTICA E FILOLOGIA, 15., 2011, Rio de Janeiro. Cadernos do CNLF. Rio de Janeiro: CiFEFiL, 2011, v. XV, n. 5, t. 1. p. 835845. Disponível em: <http://www.filologia.org.br/xv_cnlf/tomo_1/72.pdf>. Acesso em: 02 abr. 2017.

ARAÚJO, L. E. S. A variável faixa etária em estudos sociolinguísticos. In: ENCONTRO DO GRUPO DE ESTUDOS LINGUÍSTICOS DE SÃO PAULO, 26., 2007, Campinas. Caderno de Resumos. São Paulo: UNICAMP, 2007, maio-ago. p. 389 -398. Disponível em: <http://www.gel.org.br/estudoslinguisticos/edicoesanteriores/4publica-estudos-2007/sistema06/71.PDF>. Acesso em: 20 jan. 2017.

CAMACHO, R. G. Da linguística formal à linguística social. São Paulo: Parábola Editorial, 2013.

CANOVAS, M. I. F. Variação fônica de /S/ pós-vocálico e de/v, z, C * cabeças de sílaba, na fala de Salvador. 1991. 168f. Dissertação (Mestrado em Língua Portuguesa) - Programa de Pós-Graduação em Letras, Universidade Federal da Bahia, Salvador, 1991.

COAN, M.; CARVALHO, A. P. L. Relativização na escrita jurídica. Línguas e Letras, Paraná, v. 17, n. 37, p. 3-18, 2016. Disponível em: <http://e-revista.unioeste.br/index.php/linguaseletras/article/viewArticle/12675>. Acesso em: 02 abr. 2017.

GUY, G. R.; ZILLES, A. Sociolinguística quantitativa. São Paulo: Parábola, 2007.

LABOV, W. Principles of linguistic change: internal factors. Vol. 1. Oxford: Blackwell Publishers, 1994.

Sociolinguística: uma entrevista com William Labov. Tradução de Gabriel de Ávila Othero. Revista Virtual de Estudos da

Linguagem - $\quad$ ReVEL, $\quad$ v. $\quad 05, \quad$ n. $\quad 09, \quad$ ago. $\quad 2007 . . \quad$ Disponível em: <http://www.revel.inf.br/files/entrevistas/revel_9_entrevista_labov.pdf>. Acesso em 02 abr. 2017.

Padrões sociolinguísticos. Trad. Marcos Bagno, Maria Marta Pereira Scherre e Caroline Rodrigues Cardoso. São Paulo: Parábola Editorial, 2008. [1972].

MACAMBIRA, J. R. Fonologia do Português. Fortaleza: Secretaria de Cultura e Desporto, 1987.

MARQUES, S. M. O. A produção variável do fonema /v/ em João Pessoa. 2001. 96f. Dissertação (Mestrado em Linguística) Programa de Pós-Graduação em Linguística, Universidade Federal da Paraíba, João Pessoa, 2001. 
MOLLICA, M. C. Fundamentação teórica: conceituação e delimitação. In: MOLLICA, M. C.; BRAGA, M. L. (Org.). Introdução à Sociolinguística: o tratamento da variação. São Paulo: Editora Contexto, 2012 [2004]. p. 9-14.

PELICIOLI, R. A rênti tarra em carra mermo: a aspiração de fricativas na fala de Salvador. 2008. 48f. Monografia (Graduação em Letras Vernáculas) - Universidade Federal da Bahia, Salvador, 2008.

RODRIGUES, A. G. P. Ramo rê se rai dá certo: o enfraquecimento da fricativa /v/ no falar de Fortaleza. 2013. 170f. Dissertação (Mestrado em Linguística Aplicada) - Programa de Pós-Graduação em Linguística Aplicada, Universidade Estadual do Ceará, Fortaleza, 2013. Disponível em: <http://www.uece.br/posla/dmdocuments/Anagermanapontesrodrigues.pdf $>$. Acesso em: 01 abr. 2017.

RODRIGUES, A. G. P.; ARAÚJO, A. A. de; ARAGÃO, M. do S. S. de. Enfraquecimento de fricativas no Atlas Linguístico do Ceará: uma abordagem sócio-dialetal. Revista Trama: Unioeste, v. 9, n. 18, p. 53-64, 2. sem. 2013. Disponível em: $<$ https://alib.ufba.br/sites/alib.ufba.br/files/enfraquecimento_.pdf>. Acesso em: 03 abr. 2017.

RODRIGUES, A. G. P.; ARAÚJO, A. A. de. Falarra tanto que cansarra: a aspiração de /v/ no morfema verbal - ava no falar de Fortaleza-CE. Letras e Letras, Uberlândia, v. 31/2, p. 157-187, $2015 . \quad$ Disponível em: <http://www.seer.ufu.br/index.php/letraseletras/article/view/31305>. Acesso em: 01 abr. 2017.

RONCARATI, C. N.; UCHOA, J. A. C. Enfraquecimento das fricativas sonoras. In: ARAGÃO, M. do S. S de; ALMEIDA, M. R.; ARAÚJO, M. F. Projeto Dialetos Sociais Cearenses. Fortaleza: UFC, 1988.

SANKOFF, D.; TAGLIAMONTE, S. A.; SMITH, E. Goldvarb X: a multivariate analysis application. Toronto: Department of Linguistics; Ottawa: Department of Mathematics, $2005 . \quad$ Disponível em: $<$ http://individual.utoronto.ca/tagliamonte/Goldvarb.htm>. Acesso em: 10 dez. 2012.

TARALLO, F. A pesquisa sociolinguística. São Paulo: Ática, 2001 [1986].

WEINREICH, U.; LABOV, W.; HERZOG, M. I. Fundamentos empíricos para uma teoria da mudança linguística. Trad. Marcos Bagno. São Paulo: Parábola Editorial, 2006.

Recebido em 15/06/2017. Aceito em 16/10/2017. 